\title{
Correction to: Sphingadienes show therapeutic efficacy in neuroblastoma in vitro and in vivo by targeting the AKT signaling pathway
}

\author{
Piming Zhao ${ }^{1}$. Ana E. Aguilar ${ }^{1,2}$. Joanna Y. Lee ${ }^{1}$ - Lucy A. Paul ${ }^{1}$. Jung H. Suh ${ }^{1}$. Latika Puri ${ }^{1,3} \cdot$ Meng Zhang $^{1}$. \\ Jennifer Beckstead ${ }^{1} \cdot$ Andrzej Witkowski $^{1} \cdot$ Robert O. Ryan $^{1} \cdot$ Julie D. Saba ${ }^{1}$
}

Published online: 29 April 2019

(C) Springer Science+Business Media, LLC, part of Springer Nature 2019

Correction to: Investigational New Drugs (2018) 36:743-754 https://doi.org/10.1007/s10637-017-0558-5

The authors would like to note an omission of disclosure in this paper. Author JDS is cofounder, equity-holder, and consultant of GILTRx Therapeutics.

Publisher's note Springer Nature remains neutral with regard to jurisdictional claims in published maps and institutional affiliations.

The online version of the original article can be found at https://doi.org/ 10.1007/s10637-017-0558-5

Julie D. Saba

jsaba@chori.org

1 UCSF Benioff Children's Hospital Oakland, Children's Hospital Oakland Research Institute, 5700 Martin Luther King Jr. Way, Oakland, CA 94609, USA

2 Present address: Arnold Palmer Hospital for Children, $92 \mathrm{~W}$ Miller St MP 318 2nd floor, Orlando, FL 32806, USA

3 Present address: St Jude Children's Research Hospital, 262 Danny Thomas Pl, Memphis, TN 38105, USA 